\title{
Infectious pancreatic necrosis virus (IPNV) enumeration through epifluorescence microscopy: Technical aspects
}

\author{
Maria Soledad Pavlov ${ }^{1} \cdot$ Yoanna Eissler $^{1} \square \cdot$ Juan Carlos Espinoza $^{1} \cdot$ David E. Garland $^{1} \cdot$ Juan Kuznar $^{1}$ \\ 1 Centro de Investigación y Gestión de Recursos Naturales, Facultad de Ciencias, Universidad de Valparaíso, Valparaíso, Chile \\ 2 Facultad de Ciencias del Mar y de Recursos Naturales, Universidad de Valparaíso, Montemar, Viña del Mar, Chile
}

$\triangle$ Corresponding author: yoanna.eissler@uv.c

Received August 3, 2010 / Accepted December 12, 2010

Published online: January 15, 2011

(C) 2011 by Pontificia Universidad Católica de Valparaíso, Chile

\begin{abstract}
A method for counting Infectious pancreatic necrosis virus (IPNV) through epifluorescence microscopy was analyzed in detail. Image processing and statistic considerations are included. The particle size of viruses was compared in different experimental conditions such as the staining of the virus with SYBR-Green I or with antibodies for specific fluorescence labeling of viral proteins. The type of surface used as mounting support was assayed as well. The results indicated that the most suitable method involves the mounting of the viral-containing suspension on a membrane filter followed by the staining with a monoclonal antibody specific for a viral protein combined with a FITC (fluorescein isothiocyanate)-conjugated secondary antibody.
\end{abstract}

Keywords: digital image analysis, fluorescence microscope methods, immunofluorescence, Infectious pancreatic necrosis virus (IPNV), SYBR-Green I

\section{INTRODUCTION}

Viruses can be quantified by three basic approaches, counting virions as physical particles (PP), by measuring infectivity (plaque forming units (PFU) or fluorescent foci, (FF)) through the effect of virions on cells or by quantification of the protein contents or genomic RNA or DNA in purified particles. The quantification of PP and infectivity is very important because every time that a viral life cycle has been accomplished in a host as a whole or in individual cells, a mixed progeny of virions is produced; a high proportion of them correspond to virions without infective capacity. To study viral functions, is mandatory to determine the ratio between PP and infectivity, in order to asses the relevance of a given result in a research. Additionally, to determine the ratio PP/infectivity is useful to define and characterize the capacity of some viruses to produce chronic infections with virus being shed from healthy hosts. This condition, as it occurs with Infectious pancreatic necrosis virus (IPNV), depends on the progressive accumulation of interfering defective particles without infective capacity i.e., PP (De Las Heras et al. 2008).

Virus-like particles or PP can be enumerated by transmission electron microscopy (Ackermann and Heldal, 2010) but lately the most used method has become the epifluorescence microscopy because it is less time consuming, less expensive and gives more precise results than the previously mentioned method (Suttle and Fuhrman, 2010). To label viruses, different nucleic acid stains have been used such as Yo-Pro I (Hennes and Suttle, 1995), SYBR-Green I (Noble, 2001) and SYBR-Gold (Chen et al. 2001). These stains are able to detect DNA and RNA with variable sensitivity. However, sometimes the resulting samples are not bright enough to allow the counting of the viruses by direct visual observation, therefore it has been implemented the use of digital image analysis for rapid and precise enumeration of viruses (Chen et al. 2001).

IPNV is the etiological agent of a disease which causes high mortality rates in young salmonid fish, it belongs to the Birnaviridae family whose members are characterized by a genome which consists of 
two segments of double stranded RNA, named A and B. IPNV total genome size is $6 \mathrm{~kb}$ and it is enclosed in a naked icosahedral single-shelled capsid of $60 \mathrm{~nm}$ diameter (Dobos, 1995).

Fluorescence methods to titrate virus infectivity and also to count physical particles have been described for IPNV. SYBR-Green I was used to enumerate IPNV mounted on membrane filters (Osorio et al. 2005) and monoclonal antibodies were used to quantify the infectivity expressed in FF/mL which is equivalent to PFU/mL (Espinoza and Kuznar, 2002).

In this communication, we further analyze and improve the methods developed to count IPNV PP in partially purified viral suspensions. In addition, to compare different staining protocols, we describe the image processing which allows optimal counting for IPNV physical particles.

\section{MATERIALS AND METHODS}

\section{Cells and viral suspension}

To carry out the experiments, a viral stock of IPNV named UV, isolated in Chile and identified as VR299 serotype (Espinoza et al. 1985) was used. To multiply IPNV, monolayers of Chinook salmon embryo cells (CHSE-214) were grown in Eagle's minimal essential medium (EMEM) supplemented with $10 \%$ fetal bovine serum, $50 \mathrm{mg} \mathrm{L}^{-1}$ gentamicin and $2.2 \mathrm{~g} \mathrm{~L}^{-1} \mathrm{NaHCO}_{3}$ in polystyrene bottles (area: $72 \mathrm{~cm}^{2}$ ) at $20^{\circ} \mathrm{C}$. IPNV at a multiplicity of infection (m.o.i.) of $0.01 \mathrm{FF} /$ cell were inoculated to the cells monolayers and after 48-72 hrs of infection the supernatant was purified following modifications of Dobos et al. (1979) and Imajoh et al. (2003). Cells were pelleted by centrifugation at 3,020 $\mathrm{g}$ in a Sorvall rotor (SS-34) for $15 \mathrm{~min}$ at $10^{\circ} \mathrm{C}$. The viral suspension was mixed with polyethylene glycol (PEG 6,000; $60 \mathrm{~g} \mathrm{~L}^{-1}$ final concentration and $\mathrm{NaCl} 30 \mathrm{~g} \mathrm{~L}^{-1}$, final concentration) and was constantly stirred during $16 \mathrm{hrs}$ at $4^{\circ} \mathrm{C}$. Then the viral suspension was centrifuged at $72,100 \mathrm{~g}$ for $2 \mathrm{hrs}$ using a SW 28 rotor (Beckman centrifuge). The pellet obtained was resuspended in 1 or $2 \mathrm{~mL}$ of TNE buffer (10 mM Tris, $1 \mathrm{mM}$ EDTA, $100 \mathrm{mM} \mathrm{NaCl}, \mathrm{pH}$ 7.4), thereafter, an equal quantity of chloroform was added to the final viral suspension. After mixed and homogenized, the two phases were separated by centrifugation at $3,020 \mathrm{~g}$ in a Sorvall rotor (SS-34) for $10 \mathrm{~min}$ at $10^{\circ} \mathrm{C}$. Finally, an organic (lower) and aqueous phase (upper) were obtained, after this, suspension containing the purified IPNV was removed.

\section{Sample preparation to enumerate IPNV physical particles}

To measure the PP abundance in the viral suspension, SYBR-Green I and monoclonal antibodies $(\mathrm{mAb})$ specific to IPNV proteins were used. Previous to viral enumeration, $25 \mathrm{~mm}, 0.02 \mu \mathrm{m}$ pore-size Anodisc membrane filters (Whatman) were rinsed with $10 \mathrm{~mL}$ of TNE buffer. Then, $1 \mathrm{~mL}$ of viral suspension was filtered through the Anodisc membrane filters (Whatman) of $0.02 \mu \mathrm{m}$ pore-size at a pressure of $130 \mathrm{~mm} \mathrm{Hg}$. The filters were further placed on a $100 \mu \mathrm{L}$ drop of 2x SYBR-Green I (stock solution = 10,000x Molecular Probes, Inc.) and stained for 10 min following Noble and Fuhrman (1998). Filters were immersed twice in TNE buffer onto a petri dish and then mounted in a filtering tower and rinsed with $10 \mathrm{~mL}$ TNE buffer. Finally, filters were placed between glass slides and coverslips using an antifade mounting solution (DakoCytomation).

To label viral particles with antibodies, a previous step was required. The Anodisc membrane filters were immersed in $500 \mu \mathrm{L}$ of TNE with $1 \%$ fetal bovine serum (FBS) solution for $10 \mathrm{~min}$. Then filters were rinsed in a filtering tower with $10 \mathrm{~mL}$ of TNE at vacuum pressure of $130 \mathrm{~mm} \mathrm{Hg}$. Thereafter, $1 \mathrm{~mL}$ of viral suspension was filtered through the previously prepared filters. After removing the filters, they were placed facing up in a petri dish and $250 \mu \mathrm{L}$ of anti-VP3 monoclonal antibody at the final concentration of $1 \mu \mathrm{g} \mathrm{mL}^{-1}$ was added. The mAb against VP3 was produced and characterized in our laboratory (Espinoza et al. 2000). After $45 \mathrm{~min}$ at room temperature (RT), the filters were rinsed in the filtering tower three times with $10 \mathrm{~mL}$ of TNE. $250 \mu \mathrm{L}$ of polyclonal FITC (fluorescein isothiocyanate)conjugated antibody specific to anti-IgG mouse (1:80) were added to the filters and maintained during $45 \mathrm{~min}$. After incubation, the filters were rinsed with TNE as previously described. Filters were mounted between glass slides and coverslips using an antifade mounting solution (DakoCytomation). In order to avoid fading, the samples were immediately photographed. To assess for potential contamination and background fluorescence, blanks with $2 \mathrm{~mL}$ of TNE were made using both types of labels. 


\section{Digital image analysis}

To analyze labeled samples, ten optical fields in each of the filters were randomly selected per slide and were photographed at 1000x using an epifluorescence microscope (Olympus BX60F-3, WIB longpass fluorescence cube, excitation BP 460-490, beam splitter DM 505, emission BA 515IF) equipped with a Cannon Power Shot G5 camera.

Digital images (resolution 2,592 x 1,944 pixels) were processed using Adobe Photoshop CS2 version 9.0 and Image Pro Plus version 4.5. First, contrast and brightness of the images were adjusted using Adobe Photoshop to further change them to gray scale tones. To homogenize the background "flatten dark background" of Image Pro Plus software tool was used. Finally, the viral particles contrast was adjusted resulting thus in an image with well-defined black dots on a white background (Figure 1).
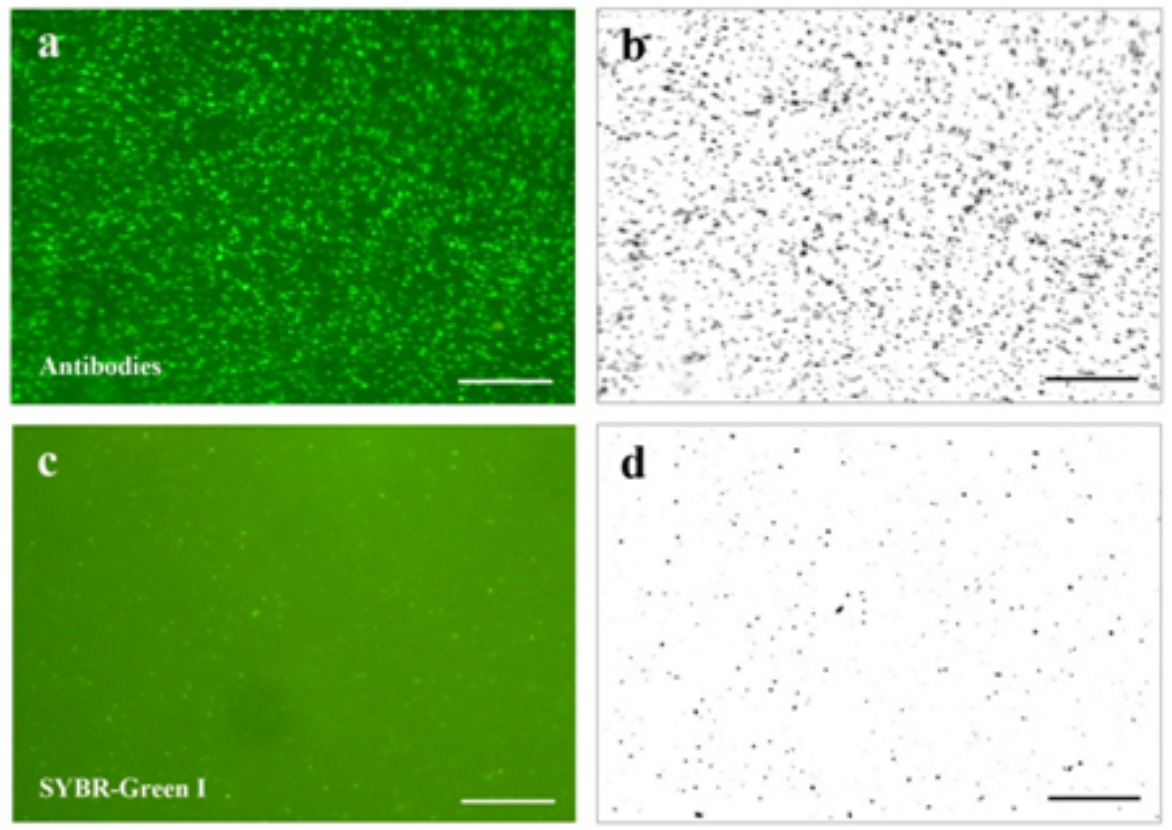

Fig. 1 Digital images of fluorescent IPNV. (a) IPNV mounted on a membrane filter and labeled with $\mathrm{mAb}$, total PP per filter was 3.6 [ \pm SE 0.34] $\times 10^{7}$, (b) IPNV processed digital image corresponding to the image in (a), (c) IPNV mounted on a membrane filter and labeled with SYBR-Green I, total PP per filter was 0.98 [ \pm SE 0.15] x 10 and (d) IPNV processed digital image corresponding to the image in (c). Scale bars: $10 \mu \mathrm{m}$.

\section{Size calibration and enumeration of fluorescence particles}

To be able to use Image Pro Plus software to count viruses, calibration was required to determine the pixel range of IPNV size. In order to check whether variations in size range were produced by the use of different mounting surfaces, viruses were visualized in cellular monolayers and Anodisc membrane filters. The virus was labeled with SYBR-Green I and/or with specific primary monoclonal antibodies and their respective secondary FITC-labeled antibodies. For calibration purposes IPNV size in pixels was compared with fluorescent spheres (Tetraspeck ${ }^{\text {TM }}$, Molecular probes, Inc; size: $100 \mathrm{~nm}$ of diameter) and $\lambda$-like bacteriophage of a known particle size (capsid size: $100 \mathrm{~nm}$ ). Two suspensions of fluorescent spheres of $5 \mu \mathrm{L}$ containing $9 \times 10^{7}$ and $9 \times 10^{6}$ spheres were prepared. The suspensions were spread in a circular area of approximately $12 \mathrm{~mm}$ of diameter on glass slides with the tip of a pipette. After drying, the area was covered with antifade mounting solution and the corresponding coverslip. In addition, fluorescent spheres suspensions of $500 \mu \mathrm{L}$, containing $5.4 \times 10^{7}$ spheres were filtered through Anodisc membrane filters using the same protocol described above for IPNV. Additionally, $\lambda$-like bacteriophage suspensions were prepared in $500 \mu \mathrm{L}$ of TNE buffer, containing $2 x$ $10^{6}$ and $2 \times 10^{5} \mathrm{PFU}$, respectively. Each suspension was filtered onto an Anodisc membrane filter and stained with SYBR-Green I following the protocol previously described for IPNV. 
In order to count IPNV physical particles bound to cells, $300 \mu \mathrm{L}$ of viral suspension $\left(2.8 \times 10^{7} \mathrm{FF} / \mathrm{mL}\right)$ were added to $12 \mathrm{~mm}$ round coverslips containing pre-confluent cell monolayers and were incubated at $4^{\circ} \mathrm{C}$ during $1 \mathrm{hr}$. After the incubation period, the cells were washed two times with PBS buffer (8.1 mM $\mathrm{Na}_{2} \mathrm{HPO}_{4}, 1.47 \mathrm{mM} \mathrm{KH}_{2} \mathrm{PO}_{4}, 2.68 \mathrm{mM} \mathrm{KCl}, 137 \mathrm{mM} \mathrm{NaCl}, \mathrm{pH}$ 7.2) supplemented with $0.5 \mathrm{mM} \mathrm{MgCl}$ and $0.9 \mathrm{mM} \mathrm{CaCl}_{2}$. Then, cold methanol was used to fix the cells at RT. Finally, viruses were labeled with $\mathrm{mAb}$ in the same conditions as described for the IPNV PP retained on membrane filters.

Fluorescent spheres, $\lambda$-like bacteriophages samples and IPNV physical particles bound to cells monolayers were photographed and analyzed using digital imaging processing, following the same methodology described above. To enumerate fluorescent particles from the digital images, Image Pro Plus software was used. In order to do this, it was first necessary to determine the size distribution frequency range (unit: pixel) of fluorescent spheres, $\lambda$-like bacteriophage and IPNV. These ranges were used as initial values (e.i., minimum and maximum values of size in pixels) in the Image Pro Plus software to obtain the total number of particles from each digital image. For IPNV PP labeled with mAb or SYBR-Green I, regardless the mounting surface used, particles sizes of 1 pixel were considered as artifacts of the method, thus they were excluded from the analysis.

To determine whether particles size distribution was normal, the Kolmogorov-Smirnov test was used; this analysis showed that size distributions for fluorescent spheres, $\lambda$-like bacteriophage and IPNV were not normal $(p<0.001)$. In consequence, to establish the particle size range it was necessary to calculate the percent cumulative frequency (Figure 2). The lower limit of the size range was determined as the smallest particle size (given in pixels) and the upper limit was set up at the $95 \%$ percent of the cumulative frequency curve (Figure 2), since the occurrence of PP drastically decrease above this limit. In order to calculate the total number of particles contained in each viral suspension, it was followed the procedure described in Noble (2001) based on the assumption that the particles have a homogeneous distribution on the surface of the membrane filters. For each sample analyzed it was calculated the confidence interval of 95\%, standard error of total PP, and the sample error (Zar, 2010).

\section{RESULTS AND DISCUSSION}

Particle size in pixels slightly varies in relation to the mounting surface and label used, ranging from 1 or 2 to 58 pixels (Figure 2). The widest particle size range distribution determined was the one corresponding to IPNV mounted on membrane filter and labeled with mAb (Figure 2e). In general, particle size range was narrower when more regular mounting surfaces were used such as glass slides and cellular monolayers (Figure $2 a$ and Figure 2d) in comparison to membrane filters (Figure 2b, Figure 2c and Figure 2e) with the exception of IPNV stained with SYBR-Green I mounted on membrane filters (Figure 2f). This could be due to the fact that less focal planes are presented on the glass slides and cells under microscope observation in comparison to membrane filters. IPNV labeled with immunofluorescence on cellular monolayer presented a narrower and smaller particle range (2-26 pixels) (Figure 2d) than the ones mounted on membrane filters (2-58 pixels) (Figure 2e). The dispersion of particles size is likely more related to the different focal planes in which they are positioned on the mounting surfaces than the size it self, this creates differences in the fluorescence signal intensity of the particles. Particles labeled with mAb mounted on filters presented broader particle size range than the ones labeled with SYBR-Green I, as it is shown in Figure 2e and Figure 2f, respectively. The bigger size of IPNV labeled with immunofluorescence can be explained by the fact that a new protein coat is being added to the virus, the primary and secondary antibody may contribute to increase the apparent size of IPNV. Osorio et al. (2005) reported a virus size range distribution of 19 pixels for IPNV labeled with SYBR-Green I and mounted on membrane filters. The particles size range shown in this paper, compared to the one of the previous report, illustrate the fact that the resolution of the device used to capture images determines the pixel size range of the particles.

IPNV and $\lambda$-like bacteriophage particles sizes range were very similar, however, the particle size at which the increase in the percent cumulative frequency started to rise for IPNV is 2 to 6 pixels (Figure 2f), but for $\lambda$-like bacteriophage the increased started between 13 to 18 pixels (Figure 2c). Therefore, the difference in size between IPNV and $\lambda$-like bacteriophage, currently described for them in the scientific literature as 60 and $100 \mathrm{~nm}$ respectively, is consistent with the size differences which are shown in this paper. 
a

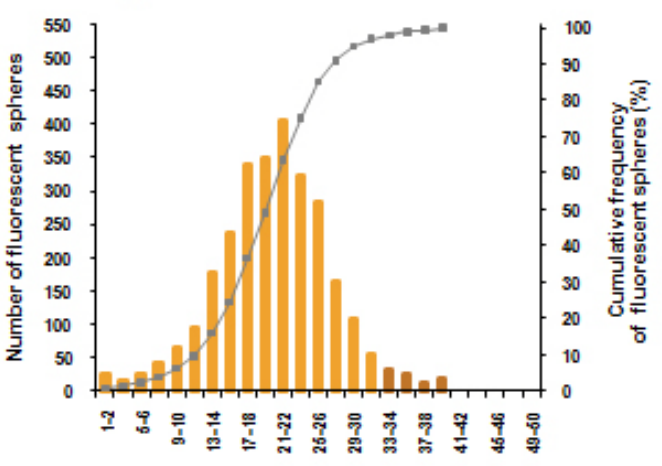

b

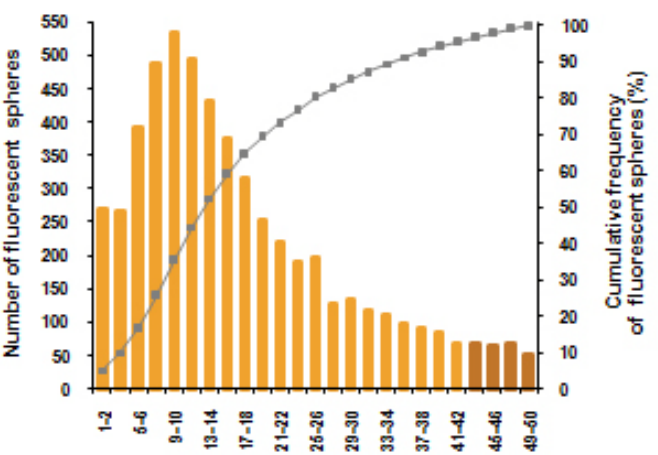

C

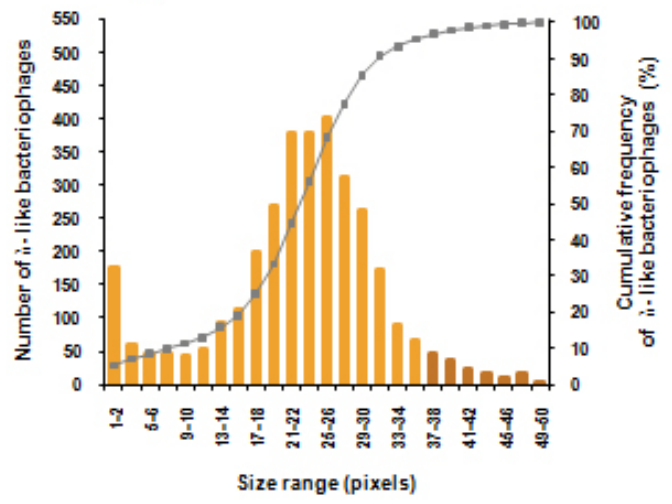

d

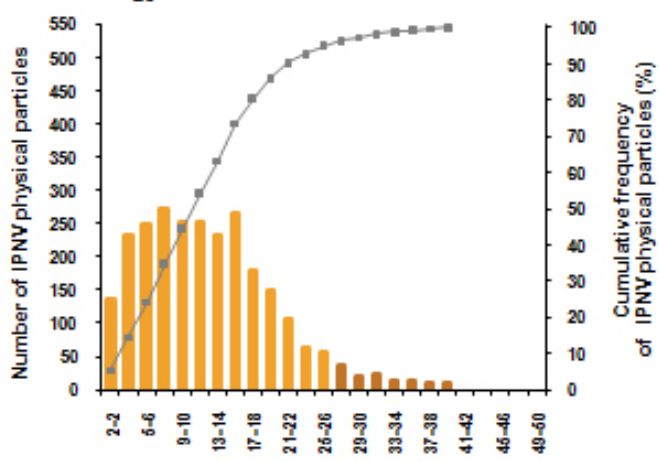

e

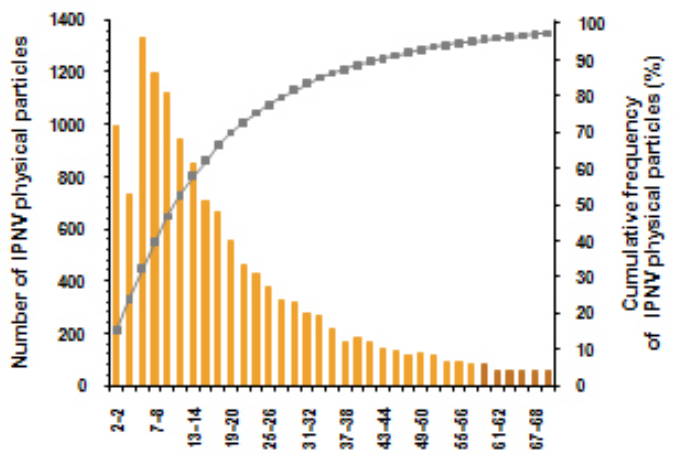

f

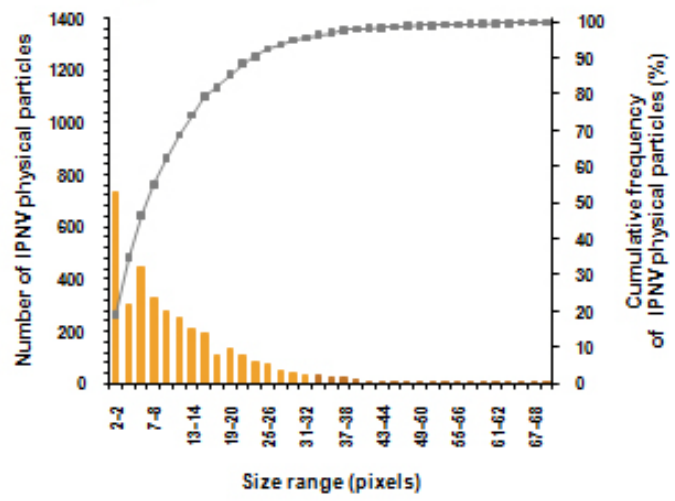

Fig. 2 Percent cumulative frequency plots. (a) Fluorescent spheres mounted on glass slides, (b) Fluorescent spheres mounted on membrane filters, (c) $\lambda$-like bacteriophage labeled with SYBR-Green I and mounted on membrane filter (d) IPNV adsorbed on cells and labeled with mAb, (e) IPNV mounted on membrane filters labeled with $\mathrm{mAb}$ and (f) IPNV mounted on membrane filters labeled with SYBR-Green I. Dark orange bars correspond to size range distribution for each type of fluorescent particles counted. Light orange bars correspond to the size range that was excluded from the analysis (according to the upper limit criteria). Gray dotted lines indicate the percent cumulative frequency of fluorescent particles examined.

When IPNV is labeled with immunofluorescence and mounted on a membrane filter, a higher total When IPNV is labeled with immunofluorescence and mounted on a membrane filter, a higher total number of PP; $3.6\left[ \pm\right.$ SE 0.47] $\times 10^{7}$ and a broader particle size distribution (Figure 2e) was found when compared with the samples labeled with SYBR-Green I (Figure 2f) where the total number of PP were generally less abundant: $2.9[ \pm$ SE 0.23$] \times 10^{7}$ (Table 1). Plausible explanations are that more densely packed viruses are less prone to allow SYBR-Green I to enter the particles and stain the viral RNA and/or that some viral particles are packed without RNA or incomplete genomes. Another 
explanation is that the staining protocol for SYBR-Green I is too close to the detection limit for a small virus such as IPNV (size: $60 \mathrm{~nm}$, genome size: $6 \mathrm{~kb}$ ). It has been reported that, using flow cytometry with viruses smaller than $40 \mathrm{~nm}$ that harbor DNA or RNA genomes of small sizes $(<15 \mathrm{~kb})$, the limit of detection for both the instrument and the staining protocol was probably reached (Brussaard et al. 2000, Tomaru and Nagasaki, 2007). On the other hand, brighter and more intensely labeled particles are obtained by immunofluorescence allowing a better enumeration through epifluorescence microscopy. In this experiment, IPNV was labeled with anti-VP3 mAb, but anti-VP2 mAb may be used as well. Nevertheles, anti-VP2 mAb gave smaller fluorescent spots than those obtained with the mAb against VP3. As the labeled particles size is close to the limit that can be visualized by immunofluorescence microscopy we preferred to use the mAb anti-VP3 in all the experiments. Indeed, IPNV is a rather small virus, around $60 \mathrm{~nm}$ diameter, it was proposed that $50 \mathrm{~nm}$ represents the lower limit allowing the direct visualization of fluorescent viruses (Pizzato et al. 2001). Therefore, each investigator aiming to quantify IPNV, and other viruses as well, should select the antibodies giving the best signals.

Avoiding fading is another concern that makes immunofluorescence labeling a better method to enumerate IPNV. Samples stained with SYBR-Green I faded faster, 2-5 sec, in comparison to samples labeled by immunofluorescence where fluorescence lasted up to $10 \mathrm{sec}$. This is very important in order to be able to capture digital images with a good quality.

In all the experiments performed, a good relationship between the dilution of samples containing virus and the number of particles counted on membrane filters was obtained. For example, we enumerated the viral particles staining them with SYBR-Green I before and after a 4-fold dilution of the suspension. A ratio of 3.8 was obtained which is very close to the value expected. Regarding the labeling procedure with $\mathrm{mAb}$; after diluting 10 -fold a viral sample; a ratio of 8.7 resulted as well.

In our experience, the lower quantity of particles that the immunofluorescence method allows to count is $4.0 \times 10^{5}$ viruses (i.e., 50 particles per field at $1000 \times$ magnification) and the highest quantity is $1.8 \times$ $10^{8}$ viruses (i.e., 23,000 particles per field at 1000x magnification). Samples containing more than this amount showed too many viral particles overlapped, making difficult the use of Image Pro Plus software for the image analysis. Instead, as it was already pointed out, when the same samples were analyzed using SYBR-Green I, the number of particles decreased in comparison to the immunofluorescence labeled particles (Table 1), with a notoriously lower overlapping.

We found that if more than $1.8 \times 10^{8}$ viruses were added to the membrane filters, viral aggregates were frequently seen. However, below this upper limit, the number of viral aggregates containing more than 1 PP decreased to less than $5 \%$ of the virus load. In addition, the viral aggregates are visualized as fluorescent dots bigger than the size range determined for the particles, with the exception of IPNV labeled with $\mathrm{mAb}$ (Figure 2e), where some viral aggregations were included within the size range determined for these particles. In cases like this, we recommend the scanning of the entire picture to visualize particles of bigger size and enlarge them to check whether they correspond to one larger particle or to a viral aggregation, to then multiply PP counted in this size range by the specific number of viruses contained within each fluorescent dot.

Table 1. IPNV physical particles (PP) counted on membrane filters using immunofluorescence (mAb) and SYBR-Green I.

\begin{tabular}{ccc}
\hline Descriptive Statistics & Immunofluorescence $(\mathbf{m A b})$ & SYBR-Green I \\
\hline Average PP per field $(\mathrm{n}=10)$ & 4,481 & 3,624 \\
\hline Total PP per filter & $3.6 \times 10^{7}$ & $2.9 \times 10^{7}$ \\
\hline Standard Error of total PP & $0.47 \times 10^{7}$ & $0.23 \times 10^{7}$ \\
Confidence interval $(\alpha=0.05)$ & $3.1 \times 10^{7} ; 4.0 \times 10^{7}$ & $2.7 \times 10^{7} ; 3.1 \times 10^{7}$ \\
\hline Sample error & $0.21 \times 10^{7}$ & $0.10 \times 10^{7}$ \\
\hline
\end{tabular}


Finally, the use of SYBR-Green I to label viral communities is inexpensive and less time consuming than other methods like electron microscopy (Noble, 2001). However when it is required to count specific viruses such as IPNV, particles are better visualized and more accurately counted using specific methods involving the labeling of PP with specific antibodies such as the monoclonal antibody and FITC-conjugated secondary antibody used in this work.

Financial support: Innova Chile/CORFO, grant 05 CT6IPD-22 (2008-2011) and Universidad de Valparaíso, Chile, grant DIPUV 11/2007.

\section{REFERENCES}

ACKERMANN, H.W. and HELDAL, M. (2010). Basic electron microscopy of aquatic viruses. In: WILHELM, S.; WEINBAUER, M. and SUTTLE, C. eds. Manual of Aquatic Viral Ecology. Waco, American Society of Limnology and Oceanography, p. 182-192. [CrossRef]

BRUSSAARD, C.; MARIE, D. and BRATBAK, G. (2000). Flow cytometric detection of viruses. Journal of Virological Methods, vol. 85, no. 1-2, p. 175-182. [CrossRef]

CHEN, F.; LU, J.; BINDER, B.J.; LIU, Y. and HODSON, R.E. (2001). Application of digital image analysis and flow cytometry to enumerate marine viruses stained with SYBR gold. Applied and Environmental Microbiology, vol. 67, no. 2, p. 539-545. [CrossRef]

DE LAS HERAS, A.I.; RODRÍGUEZ, S. and PÉREZ-PRIETO, S.I. (2008). Salmonid fish viruses and cell interactions at early steps of the infective cycle. Journal of Fish Diseases, vol. 31, no. 7, p. 535-546. [CrossRef]

DOBOS, P.; HILL, B.J.; HALLETT, R.; KELLS, D.T.; BECHT, H. and TENINGES, D. (1979). Biophysical and biochemical characterization of five animal viruses with bisegmented double-stranded RNA genomes. Journal of Virology, vol. 32, no. 2, p. 593-605.

DOBOS, P. (1995). The molecular biology of infectious pancreatic necrosis virus (IPNV). Annual Review of Fish Diseases, vol. 5, p. 25-54.[CrossRef]

ESPINOZA, E.; FARÍAS, G.; SOLER, M. and KUZNAR, J. (1985). Identity between infectious pancreatic necrosis virus VR-299 and a Chilean isolate. Intervirology, vol. 24, no. 1, p. 58-60. [CrossRef]

ESPINOZA, J.C.; HJALMARSSON, A.; EVERITT, E. and KUZNAR, J. (2000). Temporal and subcellular localization of infectious pancreatic necrosis virus structural proteins. Archives of Virology, vol. 145, no. 4, p. 739-748. [CrossRef]

ESPINOZA, J.C. and KUZNAR, J. (2002). Rapid simultaneous detection and quantitation of infectious pancreatic necrosis virus (IPNV). Journal of Virological Methods, vol. 105, no. 1, p. 81-85. [CrossRef]

HENNES, K.P. and SUTTLE, C.A. (1995). Direct counts of viruses in natural waters and laboratory cultures by epifluorescence microscopy. Limnology and Oceanography, vol. 40, no. 6, p. 1050-1055. [CrossRef]

IMAJOH, M.; YAGYU, K.I. and OSHIMA, S.I. (2003). Early interactions of marine birnavirus infection in several fish cell lines. Journal of General Virology, vol. 84, no. 7, p. 1809-1816. [CrossRef]

NOBLE, R.T. and FUHRMAN, J.A. (1998). Use of SYBR Green I for rapid epifluorescence counts of marine viruses and bacteria. Aquatic Microbial Ecology, vol. 14, no. 2, p. 113-118. [CrossRef]

NOBLE, R.T. (2001). Enumeration of viruses. Methods in Microbiology, vol. 30, p. 43-51. [CrossRef]

OSORIO, M.; ESPINOZA, J.C. and KUZNAR, J. (2005). Visualization of infectious pancreatic necrosis virus (IPNV) particles labeled with fluorescent probes. Journal of Virological Methods, vol. 130, no. 1-2, p. 140-144. [CrossRef]

PIZZATO, M.; BLAIR, E.D.; FLING, M.; KOPF, J.; TOMASSETTI, A.; WEISS, R.A. and TAKEUCHI, Y. (2001). Evidence for nonspecific adsorption of targeted retrovirus vector particles to cells. Gene Therapy, vol. 8, no. 14, p. 1088-1096. [CrossRef]

SUTTLE, C.A. and FUHRMAN, J.A. (2010). Enumeration of virus particles in aquatic or sediment samples by epifluorescence microscopy. In: WILHELM, S.W.; WEINBAUER, M.G. and SUTTLE, C.A. eds. Manual of Aquatic Viral Ecology. American Society of Limnology and Oceanography, p. 145-153.[CrossRef]

TOMARU, Y. and NAGASAKI, K. (2007). Flow cytometric detection and enumeration. Journal of Oceanography, vol. 63, no. 2, p. 215-221. [CrossRef]

ZAR, J. Biostatistical analysis. (2010). Upper Saddle River. New Jersey, Prentice Hall Inc. 944 p. ISBN 978-0-13100846-5. 


\section{How to cite this article:}

PAVLOV, M.S.; EISSLER, Y.; ESPINOZA, J.C.; GARLAND, D.E. and KUZNAR, J. (2011). Infectious pancreatic necrosis virus (IPNV) enumeration through epifluorescence microscopy: technical aspects. Electronic Journal of Biotechnology, vol. 14, no. 1. http://dx.doi.org/10.2225/vol14-issue1-fulltext-11

Note: Electronic Journal of Biotechnology is not responsible if on-line references cited on manuscripts are not available any more after the date of publication. Supported by UNESCO / MIRCEN network. 